\title{
Desarrollo Profesional Docente para la Inclusión: Investigación Acción Colaborativa a través de Estudios de Clase en Escuelas Chilenas
}

\section{Teacher Professional Development for Inclusion: Collaborative Action Research through Lesson Study in Chilean Schools}

\author{
Cynthia Duk ${ }^{1, *}$ \\ Rosa Blanco ${ }^{1}$ \\ Fiorella Zecchetto ${ }^{1}$ \\ Carla Capell ${ }^{1}$ \\ Mauricio López ${ }^{2}$ \\ ${ }^{1}$ Universidad Central de Chile, Chile \\ ${ }^{2}$ Universidad de Chile, Chile
}

\begin{abstract}
La investigación acción colaborativa ha mostrado ser relevante para avanzar hacia prácticas inclusivas pertinentes a la diversidad de estudiantes. Este estudio se basa en una experiencia de desarrollo profesional docente situado, realizada en 15 escuelas municipales, aplicando la metodología de Estudio de Clase (EC). El objetivo fue valorar los aportes del EC al desarrollo docente desde un enfoque inclusivo, los cambios que ha promovido en las concepciones y prácticas pedagógicas, y los factores que favorecen su sostenibilidad. Desde un enfoque descriptivo- interpretativo, los datos se recogieron a través de tres grupos focales en los que participaron 12 docentes de 5 escuelas y 9 facilitadores, además de análisis documental de los informes EC. Se realizó un análisis de contenido temático en base a categorías teóricas relevantes. Los resultados muestran una alta valoración del EC como estrategia para la inclusión, destacando que su mayor valor radica en la oportunidad de reflexionar y abordar problemáticas de la práctica mediante la colaboración entre pares. Asimismo, permitió a los docentes ampliar su concepción de diversidad, tomar conciencia sobre la importancia de considerar la voz de los estudiantes en las decisiones pedagógicas y trasladar el foco desde la enseñanza al aprendizaje y la participación del alumnado.
\end{abstract}

Descriptores: Desarrollo profesional; Educación inclusiva; Investigación-acción, Estudio de clase; Trabajo colaborativo.

Collaborative action research is effective to develop inclusive practices that offer relevant responses to students' diversity. This research is based on an experience of teacher professional development carried out in 15 public schools of a municipality, by applying the Lesson Study (LS) method. The objective was to assess: the contributions of LS to teacher development with an inclusive approach, the changes in pedagogical views and practices it has promoted, and the factors that facilitate its sustainability. From a descriptive-interpretative approach, the data were collected through three focus groups in which participated 12 teachers from 5 schools and 9 facilitators, and documentary analysis of LS reports. The results show a positive appraisal of LS as a strategy for inclusion, highlighting that its greatest value lies in the opportunity to reflect and address problems of practice through collaboration between teachers. It also allowed teachers to broaden their conception of diversity, to become aware of the importance of considering the voice of students in pedagogical decisions, and to move the focus of attention from teaching to students' learning and participation.

Keywords: Professional development; Inclusive education; Action research; Lesson study; Collaborative work. 


\section{Introducción}

El desarrollo profesional docente con foco en la educación inclusiva es una tarea de primera importancia para instalar capacidades en las escuelas que les permitan enfrentar los múltiples desafíos que implica la enseñanza en entornos educativos cada vez más heterogéneos y de mayor complejidad. Existe evidencia que una escuela que reconoce y valora la diversidad, como una oportunidad de aprendizaje para todo el estudiantado, requiere que los docentes pongan en acción un conjunto de actitudes y capacidades que les permitan diversificar los procesos de enseñanza aprendizaje y de evaluación, y promover interacciones positivas en un ambiente de colaboración y apoyo mutuo entre estudiantes y profesores (González-Gil et al., 2013; Shama y Mullik, 2021).

La función docente ha sido descrita como una labor altamente compleja y demandante, a la vez que crucial para el desarrollo de culturas y prácticas inclusivas en las escuelas. Los docentes en la actualidad no solo tienen que implementar un currículo más exigente, sino que deben hacerlo con grupos de estudiantes muy diversos -en cuanto a motivaciones, intereses, capacidades, procedencia sociocultural, niveles y estilos de aprendizaje- muchas veces distantes de las expectativas y competencias de sus profesores. No basta con el dominio del contenido disciplinar y la didáctica, es necesario además que los docentes sean proclives a la inclusión y manejen un repertorio amplio de estrategias de enseñanza para favorecer el aprendizaje y participación de la diversidad del alumnado (Blanco, 2015; Duk, 2014).

Lo anterior pone en el centro la preocupación por la calidad y pertinencia de los modelos y programas de formación continua, su efectividad y coherencia con los principios de inclusión. Diversos estudios en el ámbito nacional e internacional relevan que una de las mayores barreras que enfrentan las escuelas y sus docentes para avanzar hacia practicas más inclusivas, se relaciona con su percepción de autoeficacia. Los docentes no se sienten preparados ni con suficientes herramientas para trabajar con todos los/as estudiantes en contextos de diversidad y, en particular, para atender las necesidades educativas especiales que algunos pueden presentar (Castillo y Miranda, 2018; Cisternas y Lobos, 2019; González-Gil et al., 2016). En Chile, como en otros países latinoamericanos, se han invertido cuantiosos recursos en programas de formación y desarrollo docente en materia de educación inclusiva. Sin embargo, pese a los esfuerzos de los países, estas iniciativas han sido insuficientes y han tenido un escaso impacto en la modificación de las concepciones y prácticas educativas para asumir el cambio de paradigma que implica la educación inclusiva (Blanco, 2015).

Las nuevas tendencias de formación continua entienden el aprender a enseñar en y desde la diversidad como un proceso de aprendizaje profesional colaborativo y contextualizado, que se lleva a cabo en comunidades educativas que generan las condiciones para que los docentes indaguen y reflexionen sobre sus prácticas y desarrollen nuevas comprensiones y estrategias de enseñanza, que favorezcan la participación y aprendizaje de todos los estudiantes (Montecinos, 2003; Simón et al., 2018; Vaillant, 2016).

La investigación que da origen a este artículo se sitúa en la experiencia de formación y desarrollo profesional docente, realizada en el marco del Diplomado en Inclusión Educativa y Diversidad por el Centro de Desarrollo e Innovación en Educación Inclusiva de la Universidad Central de Chile, en colaboración con la Corporación Municipal de Educación de la comuna de Peñalolén (CORMUP) Santiago (2018-2020). El modelo de formación implementado se diseñó integrando aquellas estrategias de desarrollo docente 
que la literatura considera efectivas para producir transformaciones, incluyendo la metodología del Estudio de Clase (EC) ${ }^{1}$ como una estrategia de reflexión acción colaborativa para el desarrollo de prácticas inclusivas. Las que se indican a continuación:

- Formación situada en escuelas de un territorio y contextualizada: el programa se desarrolló con grupos de 3 a 6 docentes de los 15 centros educativos de la comuna (76 directivos y docentes).

- Formación sostenida en el tiempo que combina teoría y práctica: se combinó fase intensiva con Talleres semanales en dependencias de la CORMUP. Se impartieron 4 módulos del diplomado con una duración de 324 horas: M1 Inclusión educativa y diversidad; M2 Gestión y diversificación curricular; M3 Evaluación del aprendizaje y la enseñanza; M4 Sistemas y recursos de apoyo al aprendizaje.

- Formación que promueve la reflexión en la acción y la observación entre pares como recurso de aprendizaje y apoyo mutuo: se implementó el Estudio de clase como estrategia para mejorar y enriquecer la respuesta a la diversidad en el aula, la experiencia abarcó 24 equipos de EC.

- Formación que incluye acciones de acompañamiento en terreno para introducir cambios en las prácticas: se realizaron 3 visitas a cada una de las escuelas para apoyar el proceso de EC, por los formadores desde un rol de facilitador/a.

En el marco de esta experiencia, la investigación que aquí se presenta tiene como propósito valorar la metodología del EC como estrategia formativa y sus aportes al desarrollo profesional docente para la implementación de prácticas inclusivas en el aula. El EC es un proceso de investigación acción colaborativa en el que equipos de profesores planifican, enseñan, observan y analizan colaborativamente sus clases, recibiendo retroalimentación de sus pares, lo cual favorece la generación de conocimientos desde y para la práctica (Norwich et al., 2021; Vermunt et al., 2019).

Realizar una investigación sobre la implementación del EC representa una oportunidad por varias razones. En primer lugar, porque no existen estudios sobre esta metodología en Chile que abarquen todas las escuelas públicas de un territorio y que tengan como foco el aprendizaje y la participación de la diversidad de estudiantes. Existe un estudio previo, realizado por Duk y Hernández (2020), que recogió la experiencia del EC llevada a cabo en dos escuelas de Peñalolén en el marco de la anterior edición del Diplomado, cuyo objetivo fue comprender los sentidos y significados que un grupo de 7 docentes y profesionales de apoyo le otorgaban a este proceso.

Dado que el EC es una estrategia escasamente estudiada en Chile, la relevancia de esta investigación radica en su contribución al conocimiento sobre los principales aportes para el desarrollo profesional docente, los cambios que ha promovido en sus concepciones y prácticas pedagógicas, y los factores que favorecen o dificultan su implementación y continuidad. Un elemento distintivo de esta investigación es que, además de los docentes,

\footnotetext{
${ }^{1}$ Adaptado al castellano del término "Lesson Study". Estrategia utilizada originalmente en Japón y que se ha diseminado a numerosos países, dando lugar a diversas adaptaciones y variantes en su aplicación.
} 
incluyó como participantes a los formadores facilitadores quienes implementaron acciones de acompañamiento in-situ.

\section{Marco teórico}

El mayor desafío que enfrentan los sistemas educativos en la actualidad es garantizar condiciones de equidad para todos y todas respetando al mismo tiempo la diversidad humana. Para alcanzar esta aspiración, inclusión y equidad han sido reconocidos como dos principios fundamentales e indisociables (Ainscow, 2020b; UNESCO, 2017; Ydo, 2020) para lograr una educación de calidad para todos, tal como ha sido refrendado por los países en el Objetivo 4 de Desarrollo Sostenible (UNESCO, 2015). La inclusión en educación es concebida como un proceso basado en el reconocimiento y respeto de la diversidad en sus múltiples expresiones, arraigado en la creencia de que toda persona tiene valor y potencial, independientemente de su origen socioeconómico, cultural, étnico, estatus migratorio, idioma, género, edad, capacidad, orientación sexual o identidad y expresión de género, religión o creencias (Manos et al., 2020), siendo responsabilidad del sistema proporcionar a todos los y las estudiantes una respuesta educativa de calidad y pertinente a sus singularidades.

Esta visión de la educación inclusiva pone en el centro del debate la complejidad y magnitud de las transformaciones que implica, entendidas desde una perspectiva sistémica, multifactorial y multidimensional, en tanto involucra al sistema educativo en su conjunto, a la totalidad de las escuelas y sus docentes, y a todos los estudiantes y sus familias.

Avanzar hacia escuelas más inclusivas que acojan a todos y aseguren su presencia, participación y aprendizaje implica cambios sustantivos en las concepciones, actitudes y prácticas del profesorado (Hernández y Marchesi, 2021; López et al., 2010) y en consecuencia en los modelos de formación inicial y continua, toda vez que avanzar en esta dirección requiere contar con docentes mejor preparados para asegurar a todos los estudiantes, sin excepción, trayectorias educativas satisfactorias.

En el campo de la formación continua y desarrollo docente con foco en la inclusión educativa, existen escasos estudios empíricos sobre las prácticas efectivas de desarrollo profesional y sobre qué iniciativas resultan más eficaces para preparar a los formadores de docentes en la atención a la diversidad (Duk et al., 2019; European Commission, 2017), existiendo consenso en la comunidad nacional e internacional que para avanzar hacia escuelas y aulas más inclusivas se requiere un nuevo perfil docente, y el desarrollo de competencias pedagógicas cuyo eje central sea la creación de entornos inclusivos que ofrezcan respuestas de calidad a la diversidad de estudiantes.

En relación con las competencias docentes, Duk y otros (2019), describen tres propuestas que tienen el valor de ser pertinentes a los actuales desafíos y contar con una sólida base conceptual en materia de educación inclusiva: Proyecto de Formación del Profesorado para la Educación Inclusiva, desarrollado por la Agencia Europea para las Necesidades Especiales y la Educación Inclusiva (2012); Council of Europe Project on Policies and Practices for Teaching Sociocultural Diversity (2009) y el Proyecto para las Prácticas Inclusivas, liderado por Lani Florian en la Universidad de Aberdeen, Escocia (2010). Las autoras, a partir de las propuestas internacionales revisadas y de las características del contexto educativo nacional y de sus políticas educativas vigentes, proponen cuatro 
competencias que todo docente debiera manejar: a) valorar positivamente la diversidad como oportunidad y recurso para el aprendizaje de todos/as desde el enfoque de derechos; b) demostrar capacidad y disposición para trabajar colaborativamente con distintos actores para el desarrollo de una comunidad educativa inclusiva; c) implementar decisiones de flexibilización y diversificación curricular ampliando las oportunidades de aprendizaje de todas y todos los estudiantes; y d) generar entornos de aprendizaje inclusivos que promuevan una convivencia respetuosa de la diversidad.

Lo anterior es consistente con las necesidades de desarrollo docente, manifestadas por directivos y profesores chilenos consultados mediante tres encuestas. El estudio TALIS de la OCDE (Encuesta Internacional sobre Enseñanza y Aprendizaje), en su versión 2018, muestra en el caso de Chile, que el $57 \%$ de los directivos y docentes participan en seminarios y cursos de formación continua, mientras $46 \%$ participan en capacitaciones basadas en el aprendizaje y observación entre pares. Es interesante observar que los docentes, en promedio en la $\mathrm{OCDE}$, reportan que una de las formas de formación continua que ha tenido un mayor impacto, es aquella basada en enfoques de colaboración para la docencia. Los datos, al igual que en el estudio TALIS 2013, reafirman que una alta proporción de profesores chilenos manifiestan tener gran necesidad de capacitación en necesidades educativas especiales (38\% en comparación con el $22 \%$ del resto de los países), como asimismo en la enseñanza en entornos multiculturales o multilingües. Por otra parte, el $68 \%$ de los docentes expresa haberse sentido preparado para enseñar en aulas heterogéneas en cuanto a las habilidades de sus estudiantes. A su vez, la consulta participativa Voces Docentes realizada por el Ministerio de Educación (CPEIP, 2017), es coincidente con los resultados de TALIS. Las necesidades de capacitación y desarrollo docente a nivel nacional reportadas están referidas a la atención de las NEE, con mención específica a capacitación en Diseño Universal para el Aprendizaje y en Adecuaciones Curriculares. Asimismo, resulta llamativo que la totalidad de los profesionales de la Dirección Provincial de Educación de la Región Metropolitana menciona necesidades formativas relacionadas con diversidad e inclusión.

La situación descrita permite sostener que el país requiere invertir mayores esfuerzos en instancias de desarrollo profesional, que ayuden a los docentes a comprender su rol profesional como aquel que debe promover una educación equitativa y de calidad para todos y todas, reconociendo que la inclusión educativa es una oportunidad para la construcción de una sociedad más justa, democrática y cohesionada (Blanco, 2014). Como se ha señalado, las políticas de formación continua y desarrollo profesional en materia de educación inclusiva no han logrado impactar de manera significativa en las actitudes y prácticas habituales de los docentes, fuertemente arraigadas como consecuencia de los modelos de formación inicial recibidos y su posterior consolidación en el desempeño docente (Duk y Hernández, 2020).

La realidad de las escuelas muestra que los docentes no suelen disponer de los espacios y tiempos necesarios para desarrollar la enseñanza en forma colaborativa, lo cual limita el aprovechamiento de las oportunidades que ofrece el aprendizaje entre pares, quedando atrapado en las aulas el conocimiento y experiencia generada en la cotidianeidad de la práctica pedagógica (Ainscow, 2016; Krichesky y Murillo, 2018). El trabajo colaborativo entre docentes en las escuelas chilenas es todavía incipiente, y existe poca evidencia al respecto. Algunos estudios de casos sobre coenseñanza, que involucran relaciones de colaboración entre docentes regulares y profesionales de apoyo, destacan la cultura de aislamiento que predomina en los centros escolares, la carencia de competencias para el 
trabajo cooperativo, y la falta de tiempo compartido entre los profesionales, como algunas de las principales barreras para la colaboración (Muñoz et al., 2015; Rodríguez, 2014; Urbina et al., 2017).

Esto contrasta con la amplia evidencia de la literatura que releva la cultura escolar colaborativa como una de las señas de identidad de las comunidades educativas inclusivas, la cual se refleja tanto en las relaciones entre los distintos estamentos como en la gestión curricular y las prácticas pedagógicas (Jortveit y Kovač, 202 1). Así, el trabajo colaborativo ha sido reconocido como una estrategia efectiva para impulsar y sostener procesos de cambio y mejora bajo una orientación inclusiva (Ainscow, 2016; Krichesky y Murillo, 2018; Messiou, 2018). En esta línea, la experiencia ha demostrado que todo proceso formativo que apuesta a un cambio colectivo para la transformación de la práctica y la innovación requiere de acompañamiento y apoyo que ayude a orientar dicho proceso y a no perder de vista su propósito; la participación y aprendizaje de todo el alumnado. Tener la oportunidad de observar diferentes formas de enseñanza, y de recibir retroalimentación sobre la propia práctica, de parte de alguien que ayude a los docentes a comprender la diferencia entre lo que están haciendo y lo que se proponen hacer o sería deseable que hicieran para una mejor respuesta a la diversidad ha sido señalado como una modalidad efectiva de desarrollo docente (Ainscow, 2005).

En ese sentido, reflexionar sobre la propia práctica y la de sus pares desafía a los docentes a ampliar el concepto de diversidad, resignificando la inclusión a partir del análisis de las dinámicas que ocurren en el aula. Es en esta reflexión, donde las concepciones sobre el aprendizaje, desde la mirada de la diversidad, se problematizan y transforman, disponiendo a los docentes a una mayor apertura al cambio y a la flexibilidad para promover una mayor participación y aprendizaje del alumnado (López et al., 2010). Para ello, es necesario ampliar y fortalecer modalidades de desarrollo profesional basadas en el territorio, que tengan en cuenta las características y problemáticas de sus escuelas, y las necesidades formativas de sus directivos y docentes. En este marco, esta investigación se sitúo en los centros educativos de la comuna de Peñalolén de Santiago, incorporando como estrategia formativa de desarrollo profesional el Estudio de Clase (EC).

El EC es una metodología específica de investigación acción colaborativa a través de estudios de clases, en la que equipos de profesores, de preferencia tríos, planifican, enseñan, observan y analizan sus clases, recibiendo retroalimentación de sus pares, lo cual favorece la generación de conocimientos desde y para la práctica. Esta metodología, constituye una estrategia efectiva de formación con base en la escuela, centrada en un proceso de mejora continua a partir de la reflexión individual y colectiva, facilitando que los/as docentes tomen conciencia sobre el aprendizaje y la participación de sus estudiantes y aprendan a partir de su experiencia (Norwich et al., 2021; Vermunt et al., 2019).

En esta investigación, se ha tomado como referente la modalidad de EC desarrollada por el equipo de investigación internacional, liderado por Messiou y Ainscow, en distintos países de la Unión Europea. Esta variante del EC sitúa en el centro de la discusión la mirada sobre la diversidad, poniendo el foco en la respuesta y participación todos los estudiantes del grupo durante el desarrollo de la clase. Un elemento clave de esta propuesta, es la participación activa de los estudiantes en el proceso y la incorporación de sus voces para hacer más inclusivas las clases (Proyecto UE: Respondiendo a la Diversidad Contando con las Voces de los Estudiantes, 2011-2014) (Messiou et al., 2016; Simón et al., 2018). 
De este modo, el desarrollo docente se nutre de los saberes y experiencia que aporta cada profesor que integra el equipo de EC, favoreciendo el diseño de experiencias de aprendizaje desde el conocimiento disciplinar de cada docente, donde se discute sobre los saberes y sus variadas orientaciones, se intercambian estrategias de enseñanza y se producen acuerdos sobre los materiales a emplear, las secuencias didácticas y los tiempos para implementarlas (Benavides y Calvache, 2013). Asimismo, pone en juego las motivaciones y el compromiso con su aprendizaje y el de sus estudiantes, favoreciendo que se cuestionen sus concepciones previas y las metodologías y estrategias que suelen implementar, en la búsqueda de aquellas que resultan más efectivas de acuerdo con su realidad.

En el contexto de la experiencia que aquí se reporta, el proceso del EC contempló cinco fases interconectadas, que configuran un ciclo de investigación acción, el que fue implementado por tríos de docentes pertenecientes a las distintas escuelas participantes en la formación. Para una mejor compresión de los resultados encontrados, se describen a continuación cada una de estas fases y sus principales características:

- Fase 1. Organización y conformación de los equipos de EC: Este primer paso tiene por objetivo definir de común acuerdo los tríos de docentes de cada escuela que integrarán los equipos de EC, así como el curso, asignatura(as) y unidad temática que se va a abordar, los roles que asumirán y el cronograma de las clases a realizar.

- Fase 2. Planificación colaborativa: el punto de partida es la discusión sobre la diversidad de estudiantes que caracteriza al curso escogido, reflexionando en torno a las siguientes preguntas: ¿Qué queremos mejorar? ¿Qué debemos tener en cuenta para lograr que todos los estudiantes se motiven, participen y aprendan? ¿Cómo hacer nuestras clases más inclusivas? Teniendo en cuenta la diversidad, planifican colaborativamente una unidad didáctica considerando de qué manera podrían recoger las opiniones de sus estudiantes para alimentar la propuesta didáctica e implicarlos.

- Fase 3. Desarrollo de la clase: un docente del equipo implementa la clase mientras los otros dos cumplen el rol de observadores no participantes, y registran sus observaciones poniendo el foco en la respuesta de los estudiantes en cuanto a ¿Qué ha motivado a los estudiantes? ¿Cómo han participado en las actividades? ¿Cómo han interactuado entre ellos? ¿Cómo han valorado la clase? ¿Qué apoyos han requerido?

- Fase 4. Reunión de reflexión, retroalimentación y mejora: el equipo, en base a las observaciones registradas, analizan la efectividad de la clase para responder a la diversidad, con el fin de mejorarla o enriquecerla para su posterior aplicación por otro integrante del equipo, siendo un elemento central de este proceso de mejora la observación entre pares.

- Fase 5. Reunión final de reflexión: a modo de cierre del ciclo de tres clases, el equipo reflexiona acerca de las implicancias y aprendizajes extraídos de la experiencia: ¿qué hemos aprendido sobre la práctica pedagógica inclusiva? ¿Cómo valoramos el trabajo colaborativo? ¿Qué nos aportó considerar las voces de los estudiantes para la mejora? ¿Cuál sería el paso siguiente para instalar este proceso de desarrollo docente en nuestra escuela? 
Las fases 3 y 4 se repiten hasta que todos los miembros del equipo hayan participado desde distintos roles completando el ciclo de investigación acción colaborativa.

Este ciclo de investigación acción tiene un gran potencial para promover cambios en las concepciones y prácticas, coherentes con los principios de inclusión y el valor de la diversidad, ya que provoca procesos colaborativos de reflexión situados en contextos reales, a partir de problemáticas vinculadas a la enseñanza definidas colectivamente para avanzar hacia culturas y prácticas más inclusivas (Ainscow y Messiou, 2017; Messiou et al., 2016).

\section{Método}

Esta investigación se basó en un enfoque cualitativo de tipo descriptivo - interpretativo. Se buscó describir y explicar los significados, acciones y aportes, que atribuyen los actores involucrados (docentes y facilitadores) al EC como herramienta para el desarrollo profesional, y para avanzar hacia prácticas educativas más inclusivas que favorezcan el aprendizaje y la participación de la diversidad del alumnado. Se indagó, asimismo, acerca del rol de los facilitadores en el proceso de acompañamiento del EC, como uno de los componentes fundamentales del modelo formativo, así como los factores que han favorecido o dificultado su implementación.

\section{Participantes}

$\mathrm{El}$ universo del estudio fueron los nueve facilitadores que acompañaron el proceso del EC y 76 docentes, mayoritariamente de los niveles de Educación Básica y Media, de las 15 escuelas públicas de la comuna que llevaron a cabo este proceso, como un componente formativo del Diplomado en Inclusión Educativa y Diversidad. De este universo, se seleccionó una muestra intencionada de 15 docentes, conformada por los integrantes de los equipos del EC, compuestos por un trío de docentes cada uno, de 5 escuelas. La selección de los participantes se hizo según los siguientes criterios:

- Equipos de EC de diferentes escuelas

- Distintos niveles o cursos donde se realizó el EC

- Clases sobre temas o contenidos variados

- Haber participado en todas las etapas del proceso del EC

- Contar con evidencias del proceso (planificación de clases, registro de observación, informe EC).

En el Cuadro 1 se muestra el número de participantes de cada una de las escuelas, el curso y las asignaturas en las que se aplicó el EC. Cabe mencionar que 3 docentes se excusaron por no poder asistir al foco grupal, participando un total de 12 docentes. 


\section{Cuadro 1}

Participantes

\begin{tabular}{cccc}
\hline Escuelas & Docentes Grupo focal & Cursos o niveles & Asignatura \\
\hline Escuela 1 & 3 docentes GF 1 & $3^{\circ}$ básico & Lenguaje \\
Escuela 2 & 3 docentes GF 1 & $7^{\circ}$ y $8^{\circ}$ básico & Matemáticas \\
Escuela 3 & 2 docentes GF 1 & $4^{\circ}$ básico & Ciencias Naturales \\
Escuela 4 & 3 docentes GF2 & $4^{\circ}$ básico & Matemáticas \\
Escuela 5 & 1 docente GF2 & $2^{\circ}$ básico & Matemáticas \\
\hline
\end{tabular}

\section{Técnicas de producción de información}

Se utilizaron técnicas cualitativas de recogida de información de fuentes primarias y secundarias, a través de grupos focales (GF) con docentes y facilitadores (Mella, 2000), y análisis documental de registros e informes de los EC elaborados por los docentes durante el proceso.

En primer lugar, se realizaron dos grupos focales (GF 1 y GF2) con docentes abarcando un total de 12 participantes de los 15 de la muestra. Se realizó asimismo un grupo focal (GF3) con los 9 facilitadores que llevaron a cabo el acompañamiento en las escuelas.

Respecto de los instrumentos, se elaboraron dos pautas temáticas para facilitar el diálogo con los participantes, que incluyeron preguntas comunes para docentes y facilitadores y otras específicas en función del rol de cada uno. Estas fueron validadas mediante juicio de expertos en metodologías cualitativas y educación inclusiva, según criterios de coherencia, pertinencia y claridad de las preguntas. A partir de las observaciones recogidas del proceso de validación, los instrumentos fueron ajustados contemplando los siguientes temas: concepciones acerca de inclusión y diversidad; valoración del EC en cuanto a sus aportes y dificultades; cambios en las prácticas; trabajo colaborativo; valoración del proceso formativo; rol y contribuciones de los facilitadores; y propuestas de mejora.

Los grupos focales fueron conducidos por dos investigadores y tuvieron una duración aproximada de dos horas. Las preguntas se abordaron de manera flexible y se procuró que todos los integrantes participaran, generándose un clima de respeto y de confianza. Las sesiones fueron grabadas y transcritas para su posterior análisis.

En segundo lugar, se realizó un análisis documental (Rapley, 2007) de los reportes de los EC de los equipos de las 5 escuelas con el objetivo de complementar el levantamiento de información primaria con análisis de fuentes secundarias. El análisis de estos informes se centró en los siguientes aspectos: concepciones sobre diversidad e inclusión; dificultades, logros y actividades realizadas en las diferentes fases del EC; trabajo colaborativo; aprendizajes del equipo con el EC; estrategias para atender a la diversidad del alumnado; e ideas emergentes.

\section{Análisis de los datos}

Se utilizó un método deductivo/inductivo, de progresivo refinamiento, estableciendo unas categorías y subcategorías iniciales, derivadas del marco teórico y de los objetivos del estudio. Estas categorías iniciales quedaron abiertas a posibles redefiniciones en función del análisis de las textualidades de los grupos focales y del análisis documental, en el que emergieron nuevas subcategorías, como el rol docente para enseñar a la diversidad, o, se subsumieron algunas subcategorías en otras más amplias, como por ejemplo planificación 
diversificada, variedad de estrategias y recursos y evaluación en diversificación de la enseñanza (Gibbs, 2012).

\section{Cuadro 2}

\section{Categorías y subcategorías de análisis}

\begin{tabular}{|c|c|}
\hline Categorías & Subcategorías \\
\hline $\begin{array}{l}\text { 1. Cambios en las concepciones y } \\
\text { prácticas }\end{array}$ & $\begin{array}{l}\text { 1.1. Ampliación de la mirada sobre diversidad } \\
\text { 1.2. Concepción de aprendizaje y rol docente para } \\
\text { enseñar a la diversidad } \\
\text { 1.3. Participación de los estudiantes y escuchar su voz } \\
\text { 1.4. Diversificación de la enseñanza } \\
\text { 1.5. Interdisciplinariedad }\end{array}$ \\
\hline $\begin{array}{l}\text { 2. Aportes del EC al desarrollo } \\
\text { profesional docente con foco en la } \\
\text { inclusión }\end{array}$ & $\begin{array}{l}\text { 2.1. Planificación colaborativa } \\
\text { 2.2. Reflexión conjunta sobre la práctica } \\
\text { 2.3. Observación y retroalimentación centrada en los } \\
\text { estudiantes }\end{array}$ \\
\hline $\begin{array}{l}\text { 3. El estudio de Clase como } \\
\text { estrategia formativa }\end{array}$ & $\begin{array}{l}\text { 3.1. Valoración del modelo de formación } \\
\text { 3.2. Proceso de acompañamiento y rol de facilitadores }\end{array}$ \\
\hline
\end{tabular}

El análisis de la información se llevó a cabo mediante los siguientes procesos de triangulación:

- Triangulación de métodos y de datos: los resultados entregados contrastan la información obtenida en los grupos focales y el análisis documental, dando cuenta de las tendencias principales y los aspectos que aparecen con mayor consistencia, así como de las divergencias

- Triangulación de actores: el análisis de los relatos de docentes y facilitadores se fue organizando en una tabla de doble entrada considerando las categorías iniciales, así como subcategorías emergentes, lo cual permitió identificar los aspectos que relevaban unos u otros, las coincidencias y divergencias, así como los vacíos de información.

- Triangulación de investigadores: todo el equipo de investigadores participó en el análisis de los datos, sus resultados y las conclusiones del estudio, evitando así el sesgo potencial derivado del análisis de los datos desde una única perspectiva.

\section{Consideraciones éticas}

Los docentes participaron en forma voluntaria y bajo consentimiento informado en las sesiones de grupos focales. Estas fueron grabadas y transcritas para su posterior análisis resguardando la confidencialidad de la información. Además, se contó con la autorización de la Corporación de Educación Municipal y de las y los directores de las escuelas participantes.

\section{Resultados}

En este apartado se analizan los resultados obtenidos en relación con las 3 categorías definidas en la investigación, con sus correspondientes subcategorías, mediante los procesos de triangulación anteriormente descritos. 


\subsection{Cambios en las concepciones y prácticas educativas}

En esta categoría se analizan los aportes del EC en relación con los cambios en las representaciones y creencias de los docentes acerca de los conceptos nucleares de la perspectiva de la inclusión, así como las principales innovaciones o cambios que éstos han implementado para avanzar hacia prácticas educativas más inclusivas, que es la principal finalidad del proceso formativo.

\subsubsection{Ampliación de la mirada sobre diversidad}

Uno de los cambios más relevantes en las creencias del profesorado ha sido la ampliación de los conceptos de inclusión y diversidad, transitando desde una noción restringida a los estudiantes con NEE, discapacidad, o problemas de aprendizaje, hacia una representación más amplia que contempla las diferencias sociales, culturales e individuales y que considera que todas y todos los estudiantes son distintos y singulares. La siguiente cita ilustra este cambio:

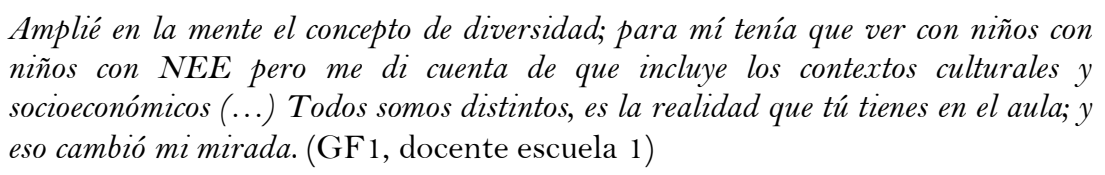

Los testimonios de docentes y facilitadores confirman este hallazgo, expresando que cuando se inició el EC las descripciones que hacían de la diversidad de los cursos se restringía a los estudiantes con algún tipo de dificultad, pese a que se había trabajado en los módulos del diplomado el concepto amplio de diversidad. Esto permite hipotetizar que el cambio conceptual se debe en buena medida al EC, gracias a los procesos de observación y retroalimentación sobre la práctica que han favorecido la toma de conciencia y la modificación de sus concepciones previas. Por ejemplo, una facilitadora planteó:

En las descripciones iniciales, la mirada de la diversidad estaba centrada en los estudiantes que tienen problemas, pero luego empezaron a mirar más a todo el grupo y cómo podían participar todos. (GF3, facilitadora 1)

El reconocimiento de que todos los estudiantes son diferentes ha supuesto un cuestionamiento del concepto de "normalidad" o "del estudiante promedio", así como de las prácticas homogeneizadoras que excluyen y etiquetan a quienes no encajan en los prototipos establecidos, relevando la necesidad de que la enseñanza se adapte a las diferencias de los estudiantes, en lugar de que éstos se adapten a las formas de enseñanza disponibles y estandarizadas. Por ejemplo, una docente comentó que:

\footnotetext{
La normalidad no existe, uno debe entrar a la sala desde la perspectiva de que hay una diversidad de personas y, cada una tiene sus necesidades, sus formas de aprender y es el profesor el que tiene que adaptarse y no los niños adaptarse al sistema, porque esa batalla es perdida. (GF1, docente escuela 1)
}

\subsubsection{Concepción de aprendizaje y rol docente para enseñar a la diversidad}

Los relatos de las y los docentes muestran una toma de conciencia respecto a que cuanto mayor es la participación de los estudiantes mayor es el aprendizaje, y que éstos no aprenden solo del docente sino también de sus iguales, compartiendo ideas, colaborando y aprendiendo de la experiencia de otros, en coherencia con el enfoque adoptado en el diplomado. Una docente comentó:

Ellos construyen a través de ellos mismos y de sus pares; para mí no es que yo sea el actor principal; yo entro y doy una introducción y una actividad y lo ideal es que ellos 
a través de sus habilidades, cada uno en forma diferente, en grupo construyan y eso para mí es el aprendizaje. (GF 1, docente escuela 1)

Los docentes destacan que muchos estudiantes tienen un bajo autoconcepto que influye de manera negativa en su aprendizaje y reduce sus expectativas de éxito en la escuela, por lo que se expresa la importancia de confiar en sus posibilidades, tener altas expectativas y una retroalimentación positiva para que confíen en sí mismos y tengan expectativas de autoeficacia. El EC ha contribuido a cambiar la mirada de los docentes sobre sus estudiantes poniendo el foco en las fortalezas más que en sus debilidades, y reconociendo la importancia de no tener expectativas preconcebidas respecto a sus posibilidades de aprendizaje. Por ejemplo, una docente razonó que:

To creo que es súper importante volver a hacerlos confiar en ellos mismos, de que hay muchas cosas que pueden aprender, o formas en las que pueden aprender" (...) Hay que enfatizar que no son problemáticos, que pueden estudiar. (GF 1, docente escuela 1)

Por su parte, un facilitador comentó que:

Se enfrentaron a grupos de niños con los que no trabajaban habitualmente y varios profesores mencionaron que se dieron cuenta de que tenían mejores expectativas hacia todo el grupo, no tenían la expectativa ya definida de que este alumno se porta mal, o tiene dificultad en tal o cual cosa. (GF3, facilitador 4)

En coherencia con lo expresado, los docentes señalan que su rol no es el de transmitir conocimientos sino facilitar, organizar y guiar el aprendizaje, y sobre todo motivar a todos los estudiantes, escuchándolos y haciéndoles partícipes en la toma de decisiones, lo cual implica un cambio en las relaciones con los estudiantes de mayor reciprocidad y complementariedad, donde el docente no es el protagonista ni el único que toma decisiones. Por ejemplo,

Nosotros no somos reproductores de una asignatura, somos guías (...) yo tengo que entrar a la sala a cautivar a mi audiencia porque de ahi va a venir todo lo demás. (GF 1, docente escuela 2)

Un aspecto muy destacado ha sido la importancia de las competencias personales y relacionales para favorecer el aprendizaje y la participación de la diversidad del alumnado, tales como la apertura, la autocrítica, la flexibilidad, el respeto de las diferencias, la empatía y el trabajo colaborativo. Se menciona asimismo que los docentes han de tener una actitud positiva, estar motivados y tener una alta autoestima porque son un modelo para los estudiantes. Un docente señala que:

[es importante] ser empático, respetuoso, o sea, respetar las diferencias de los demás, y lo otro, tener una mente abierta, abierta a los cambios, a la diversidad. (GF1, docente escuela 1)

\subsubsection{Participación de los estudiantes y escuchar su voz}

Uno de los mayores impactos del EC ha sido la toma de conciencia sobre la importancia de la participación de los estudiantes y de escuchar su voz para la toma de decisiones, ampliando su comprensión de la participación como un proceso que va más allá de emitir opiniones, experiencias, o formar parte de los centros de estudiantes. En el informe de una de las escuelas, concluyen que:

Aprendimos el impacto que tiene recoger de manera sistematizada la voz de los estudiantes y hacer de esta instancia algo más que solo preguntar ¿̇qué les gustaría aprender y cómo? (...) pudimos ver que expandiendo las formas de preguntar podemos 
obtener más información y más específica, transformando este proceso en una valiosa oportunidad. (Informe EC, escuela 2)

Este ha sido un aspecto muy destacado y el más novedoso para los docentes, quienes expresaron que el EC les sirvió para darse cuenta de que escuchaban poco a sus estudiantes y constatar que, cuando se les da la oportunidad, pueden hacer aportes muy valiosos que enriquecen los procesos de enseñanza y aprendizaje. Esta toma de conciencia se ha convertido en acción, siendo el cambio más significativo que se han producido en su práctica pedagógica.

El análisis de los relatos e informes releva que la participación se ha concretado mayormente en darles a los estudiantes la posibilidad de elegir entre varias actividades o en la forma de desarrollarlas o de expresar lo aprendido, la autoevaluación y coevaluación, así como en considerar sus puntos de vista en las planificaciones y su valoración sobre el desarrollo de las clases. Recoger la voz de los estudiantes enriqueció la práctica porque permitió obtener información muy valiosa para planificar una respuesta educativa más pertinente a sus intereses y necesidades, y retroalimentar la práctica docente. Los docentes destacan que incorporar las sugerencias de sus estudiantes, como por ejemplo jugar o usar las redes sociales, generó una mayor motivación e involucramiento en las actividades. Así, una docente reflexiona que:

Escuchamos las voces de los estudiantes y les dimos tres actividades que se abocaban al mismo objetivo, en donde ellos fueron capaces de decidir; esa clase fue la más enriquecedora, porque sentimos que ellos tenían que ser partícipes de nuestra planificación, y de verdad que eso me ayudó a cambiar mi forma de ver, de planificar $y$ de hacer pruebas. (GF 1, docente escuela 3)

\subsubsection{Diversificación de la enseñanza para atender la diversidad}

La metodología del EC ha permitido visibilizar la diversidad en el aula y tomar conciencia de que hay estudiantes que no participan, dándose pasos para la elaboración de planificaciones más diversificadas y centradas en incrementar la participación y aprendizaje de todo el grupo, aunque este es un aspecto en el que hay que seguir profundizando. Al respecto, se destaca la importancia de contar con información amplia de todos los estudiantes para tomar decisiones pertinentes a sus intereses, capacidades y necesidades.

Una de las reflexiones más fuertes e importantes que hicimos fue que hay estudiantes que pueden pasar 'eternamente' al interior de la sala como si no existieran. (Informe EC, escuela 4)

Al momento de planificar la actividad de la clase, imagino a mis estudiantes realizándola para ver las posibles formas en la que estos manifiestan su aprendizaje, para incluirlas en las instrucciones. (GF 1, docente escuela 3)

Algunos docentes mencionan como uno de los aportes del EC la utilización de los principios del Diseño Universal para el Aprendizaje (DUA), si bien otros consideran que no es fácil aplicarlos durante el desarrollo de las clases. Manifiestan, asimismo, que han ampliado su repertorio de estrategias y recursos para responder a la diversidad, gracias a la posibilidad de observar otras formas de enseñanza y de relación con los estudiantes. Varios facilitadores señalan la necesidad de fortalecer las competencias del profesorado para que sean capaces de incorporar todos los principios del DUA: diversas formas de motivar y de presentar la información, mayor variedad de estrategias y distintas formas de evaluación. No obstante, se observa una evolución desde una práctica centrada en 
adaptar la planificación del curso para algunos estudiantes, hacia planificaciones que consideran desde el inicio las necesidades y características de todo el grupo.

To también cometí el error de hacer una rúbrica diferente, de hacer planificaciones diferentes, pero el mismo estudiante, se me acercó y me dijo: profesora, a mi evalúeme igual que a mis compañeros. (GF1, docente escuela 2)

La estrategia de diversificación más empleada ha sido la de planificar varias actividades y recursos para trabajar el mismo objetivo o contenido de aprendizaje, así como la utilización de temas y materiales del entorno que tengan sentido para las y los estudiantes. Aunque esto implicó más trabajo y la elaboración de materiales adicionales, mostró resultados satisfactorios.

Una de las cosas que más me cuesta es que los niños lean, entonces les di la posibilidad de que el que quería dibujaba, el que quería relataba y el que quería narraba o dramatizaba el cuento. Fue una experiencia muy enriquecedora porque sentí que estaban todos incluidos, y quedé muy satisfecha con el resultado. (GF2, docente escuela 4)

Otro de los cambios reportados ha sido la distribución de los estudiantes dentro del aula, rompiendo con la enseñanza frontal, a pesar de los temores iniciales de perder el control del grupo, lo cual favoreció el movimiento, la participación y la colaboración entre estudiantes. Junto con ello, algunos docentes organizaron el aula en grupos heterogéneos (según diferentes habilidades académicas y sociales y con asignación de roles), lo cual constituye una innovación porque en general no manejaban estrategias para organizar los grupos que no fueran la aleatoriedad o la afinidad.

En uno de los grupos el cambio más significativo fue romper con la estructura en filas de la clase, lo cual permitió elegir espacios, el movimiento y el aprendizaje cooperativo. (GF3, facilitadora 1)

En relación con la evaluación, el cambio más destacado ha sido el uso de la autoevaluación y la coevaluación como parte de la práctica inclusiva, porque favorece un mayor protagonismo del alumnado en su proceso de aprendizaje, permite que identifiquen sus logros y dificultades, recibir retroalimentación de sus pares y profesores, y ayuda al docente a tomar decisiones sobre las estrategias a utilizar en esa y en futuras sesiones.

\footnotetext{
Cuando probamos la coevaluación, que era algo que no se había hecho nunca, ver que ellos eran capaces -sin ser hirientes, sin molestar al otro- de decir 'mira, tú trabajaste, tú no, tú hiciste esto, tú no', nos dimos cuenta de que resultó bien, que había que volver a ocuparla, pues formó también compromisos entre ellos. (GF2, docente escuela 4)
}

El análisis de los informes del EC muestra que se ha comenzado a utilizar distintas técnicas como el uso de tapas plásticas o papeles de colores para que los estudiantes señalen durante la clase si han comprendido los conceptos, si tienen dudas, si algo dificultó su aprendizaje o las tarjetas de salida para evaluar la clase una vez finalizada.

\subsubsection{Interdisciplinariedad}

$\mathrm{El}$ abordaje interdisciplinar ha sido valorado como uno de los principales aportes del EC. A pesar de las aprehensiones iniciales de planificar junto a docentes de otras asignaturas, y en ocasiones para cursos nuevos, se destaca que la integración de disciplinas favoreció una mayor motivación, aprendizaje y participación de las y los estudiantes y una riqueza para el profesorado.

La gran mayoría de los profesores con los cuales que yo trabajé se dieron cuenta de que las distintas disciplinas no son excluyentes entre sí que, por el contrario, son 
complementarias y permite hacer clases más enriquecidas, más creativas, y dinámicas que motivan más al estudiantado. (GF3, facilitador 7)

Uno de los beneficios más destacados es que favoreció la diversificación de la enseñanza, al brindar al alumnado múltiples perspectivas, materiales y profesionales para conocer un tema, y al permitirles desarrollarlo desde las capacidades e intereses personales:

Un niño a lo mejor tiene dificultad para entrar desde matemáticas, pero sí lo puede
captar desde ciencias, que es un trabajo más experimental. Yo pienso que allí es donde
también esta diversidad debe ser entendida. (GF1, docente escuela 2)

Muchos estudiantes tienen dificultades para establecer relaciones, transferir y generalizar el conocimiento cuando este se les presenta de manera parcelada, en este sentido la integración de asignaturas permitió reforzar y profundizar en los temas evitando esta fragmentación:

Si nosotros en la escuela tenemos serios problemas de lectura deberíamos estar todos cuadrados en lectura, desarrollando la compresión lectora en todas las asignaturas. Esto de ver cada asignatura parcelada, también al niño le parcela el cerebro. (GF1, docente escuela 2)

\subsection{Aportes del estudio de clase al desarrollo profesional de los docentes}

En esta dimensión se analiza específicamente el aporte de la metodología del EC al desarrollo profesional docente, en cuanto al fortalecimiento de capacidades para trabajar de forma colaborativa, planificar, reflexionar y analizar su práctica desde la perspectiva de favorecer el aprendizaje y la participación de la diversidad del alumnado.

\subsubsection{Reflexión conjunta sobre la práctica}

Se valora que el EC dio la posibilidad de problematizar y reflexionar sobre las propias prácticas, en colaboración con otros, permitiendo generar una instancia para mirarse y tomar conciencia de lo que hacían, comprender por qué lo hacían y visualizar la distancia entre lo que pensaban y lo que hacían. La reflexión en conjunto les permitió tomar conciencia de aspectos de su práctica, que no se hubiesen dado cuenta por sí solos.

Una profesora en el momento de hacer el análisis de sus clases se da cuenta de que solo es discurso, que utiliza estrategias que son tradicionales. Ella me decía: 'yo me veía innovadora, pero la verdad es que sigo trabajando tradicionalmente'. Entonces es capaz de mirarse. (GF3, facilitadora 5)

La reflexión sobre la propia práctica en espacios de colaboración es una acción que el profesorado, en general, no suele hacer dentro del desempeño de su rol habitual. En este sentido, el EC les permitió ser observadores e investigadores continuos de sus prácticas para analizarlas y transformarlas.

Tenemos muy poco tiempo para la reflexión pedagógica, yo diría que un plus de este diplomado es que nos ofrece esta oportunidad, donde nosotras tres que trabajamos en niveles distintos podamos conversar de nuestras prácticas. Por supuesto que el estudio de clase es un tremendo aporte en términos de lo que significó planificar juntas, consensuar ideas de cómo íbamos a abordar las estrategias para enfrentar la diversidad del curso. (GF1, docente escuela 3)

Aunque a las y los docentes en un principio les costaba problematizar sus prácticas, durante el proceso se observó un progreso en la capacidad de análisis y de autoevaluación, tomaron perspectiva y entendieron mejor lo que estaban haciendo y porqué lo estaban haciendo. 
Nos invitó a ponernos al servicio de la reflexión y el aprendizaje constante (...) cada una de nosotras, estábamos ahí para apoyarnos, para corregirnos, para guiarnos y para seguir avanzando (...) a comprender que la inclusión es una forma de ver el mundo. (Informe EC, escuela 3)

\subsubsection{Planificación colaborativa}

La colaboración entre docentes fue un gran aporte del EC, transformando el trabajo de planificar en forma aislada, en un ejercicio profesional que se enriqueció del acompañamiento y apoyo entre pares. Se generaron instancias de encuentro para pensar y planificar en conjunto, intercambiar experiencias y recibir retroalimentación sobre las actividades propuestas, lo que favoreció el desarrollo de clases más creativas, motivadoras y significativas para la diversidad de los estudiantes.

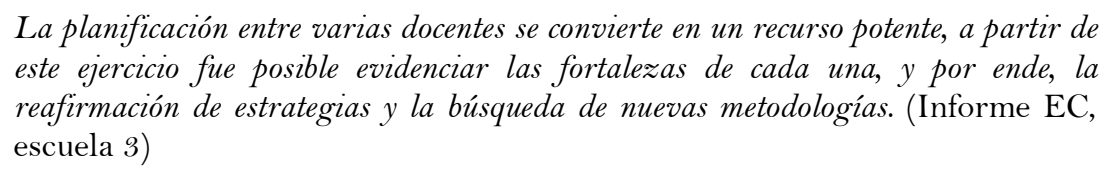

La planificación entre varias docentes se convierte en un recurso potente, a partir de este ejercicio fue posible evidenciar las fortalezas de cada una, y por ende, la reafirmación de estrategias y la búsqueda de nuevas metodologías. (Informe EC, escuela 3)

Tanto la planificación colaborativa, entre docentes de distintos niveles y asignaturas, como el trabajo en aula con otros docentes y profesionales de apoyo promovió prácticas de soporte mutuo, que les ayudaron a valorar la importancia de los aportes y la complementariedad de perspectivas de las distintas disciplinas, lo cual ha favorecido el desarrollo de clases más pertinentes y enriquecidas:

\section{Es importante cómo los profesionales [de apoyo] entran al aula junto con nosotros, porque eso para la inclusión es importantísimo: hay cosas en las que yo no tengo esas fortalezas (tengo otras) y esas fortalezas las tiene el profesional. (GF 1, docente escuela 2).}

\subsubsection{Observación y retroalimentación centrada en los estudiantes}

La etapa de observación y retroalimentación del EC fue muy significativa y valorada por todos los equipos, destacando que su práctica se enriqueció al observar otras formas de enseñanza y de relacionarse con los estudiantes. Por otro lado, poner el foco de la observación en los estudiantes constituyó una innovación para el profesorado, porque se alejó de lo que se practica habitualmente en las escuelas; instancias centradas en la evaluación de la docencia, vivenciadas con sentimientos de temor y tensión que los sitúa en una posición defensiva. Por el contrario, la observación del EC se vivenció como algo gratificante, como una actividad de crecimiento y desarrollo profesional que posibilita muchos aprendizajes.

\footnotetext{
El ejercicio mismo de estar en el aula y vernos a las tres -sin ser un acto punitivo, porque estamos tan acostumbrados a que la persona que entra a la sala entra punitivamente, y eso ya nos pone en una situación súper tensa y a la defensiva-siento que fue un ejercicio súper bonito en términos de agregar a nuestros acervos como profesora lo que la otra nos incorporaba, ver hacer clase, ver a los niños en la dinámica, ver cómo los niños reaccionaban a las diversas estrategias, creo que sin duda enriquece nuestras prácticas en el aula. (GF2, docente escuela 4)
}

Si bien los docentes reconocen el valor de la retroalimentación para el cambio de las prácticas, resaltando que el clima de confianza generado les ayudó a reducir los reparos iniciales a ser observados, desde la mirada de los facilitadores la retroalimentación resultaba a veces demasiado positiva y poco crítica. Esto podría deberse a falta de entrenamiento en la observación de clase y su registro, o al temor a hacer una valoración negativa del trabajo de los colegas que pudiera afectar las relaciones. A ello se suma que, por lo general, los docentes no hacían uso de los registros de observación con que 
contaban, lo cual podría explicar el nivel de análisis alcanzado desde una mirada más crítica.

\begin{abstract}
Yo a veces sentía que no iban a decir nada que pudiera ser un poco más crítico por miedo a valorar negativamente el trabajo de un colega (...) pero costó llegar a ese nivel de reflexión y de decir, mira podrías mejorar esto, abordémoslo de esta forma, creo que fue una de las principales dificultades que tuvo mi escuela. (GF3, facilitadora 1)
\end{abstract}

Por otra parte, aunque el EC promovía un cambio en la observación y retroalimentación poniendo el foco en el aprendizaje y las formas de participación de los estudiantes, la tendencia fue focalizar la observación en la actuación y estrategias utilizadas por el o la docente, en lugar de centrar la mirada en la respuesta de las y los estudiantes.

\begin{abstract}
Pese que el foco era la participación de todos, luego en la retroalimentación cuando preguntaba si se dieron cuenta de que había 2 o 3 niños que no participaron, que incluso había algunos que levantaron la mano varias veces y nunca les dieron la palabra, no se habian dado cuenta porque estaban mirando también otras cosas. (GF3, facilitadora 1)
\end{abstract}

\title{
4.3. El estudio de clase como estrategia de formación
}

Esta dimensión da cuenta de los resultados del análisis de los datos recogidos respecto de la valoración del modelo de formación implementado en el marco del diplomado Inclusión Educativa y Diversidad. Específicamente se analiza el aporte de la metodología de EC al proceso formativo, así como del acompañamiento realizado en las escuelas, relevando las sugerencias propuestas por los participantes para la mejora de la formación.

\subsubsection{Valoración del modelo de formación}

Los docentes manifiestan en general una satisfacción con el proceso formativo del Diplomado, porque aportó a su desarrollo profesional, tanto en lo que respecta a los contenidos abordados en los módulos y a la metodología de formación, como a la posibilidad de enriquecer sus prácticas para una mejor respuesta a la diversidad en el aula. Contribuye de manera importante a esta apreciación el EC como una experiencia novedosa con las significaciones, aprendizajes y vivencias que les proporcionó. Esta valoración positiva es coincidente con la de las y los facilitadores, para quienes el EC favoreció la integración de los conocimientos del diplomado y su aplicación a situaciones reales, permitiendo vivenciar un proceso de mejoramiento a partir de la reflexión sobre las propias prácticas.

El EC con foco en la práctica inclusiva fue abordado en los talleres de formación del Diplomado. Esta preparación previa fue percibida como muy necesaria porque permitió familiarizarse con este proceso desde el punto de vista teórico y metodológico. Docentes y facilitadores comparten la idea de asignarle más tiempo y continuidad al EC dentro del programa de formación, en la perspectiva de que pueda ser incorporado como una práctica habitual dentro de la labor docente. Al respecto, proponen que el EC sea el hilo conductor de los cuatro módulos del diplomado, lo cual favorecería una mayor integración entre teoría y práctica.

El estudio de clase podría ser el conductor del diplomado... entonces pensar en hacer el diplomado conectándolo todo el tiempo con el estudio de clase. (GF3, facilitador 7)

Que el estudio de clase partiera en los primeros días y mientras vamos adquiriendo nuevos conocimientos teóricos, los vamos mejorando en nuestras clases. Entonces la 
idea es ver como 'iGuau! Así éramos en marzo y así llegamos a diciembre; esta fue nuestra clase en marzo y ahora en diciembre’. (GF2, docente escuela 5)

Docentes y facilitadores consideran que los contenidos abordados en el diplomado son pertinentes y útiles para planificar y realizar actividades más diversificadas, pero cuestionan que la metodología empleada no ha facilitado vivenciar suficientemente los principios y estrategias que se espera que transfieran a sus prácticas. Ello plantea un desafío a los formadores en términos de fortalecer sus competencias para hacer las clases más diversificadas, incluyendo más ejemplos y demostraciones prácticas que sirvan de modelado para los participantes.

Es necesario una comprensión más profunda de lo que implica la diversificación, yo creo que eso es algo que es transversal. Es una competencia que no está tal vez en todos nosotros, y lo planteo como hipótesis, porque igual necesitamos modelar. (GF3, facilitadora 2)

Asimismo, varios docentes sugieren incluir actividades que favorezcan un mayor conocimiento e intercambio de las prácticas existentes, promoviendo el trabajo colaborativo entre docentes de distintas escuelas, ya sea visibilizándolas, dando más espacios para compartirlas, $\mathrm{u}$ otras alternativas que fortalezcan las redes entre las escuelas participantes.

Finalmente, tanto docentes como facilitadores valoran muy positivamente el material empleado para apoyar el proceso del EC y las acciones de acompañamiento. Este aspecto se releva en los informes del EC, donde se destaca la utilidad de los documentos y las pautas de observación de las clases y de revisión de las prácticas.

\subsubsection{Proceso de acompañamiento y rol del facilitador}

Un elemento distintivo del modelo de formación ha sido el acompañamiento llevado a cabo en las escuelas por los formadores facilitadores para apoyar a los equipos en la puesta en práctica de sus respectivos EC, lo cual ha sido muy valorado por el profesorado. Se releva que las actitudes y acciones de las y los facilitadores ayudaron a que el proceso del EC se llevara a cabo de buena forma, porque crearon un contexto colaborativo y cálido emocionalmente y aportaron al propósito de poner el foco en la participación y aprendizaje de la diversidad del alumnado.

Destacan el buen trato y actitudes amables y acogedoras de las y los facilitadores, que se traducen en escuchar y generar confianza, y que su función debe ser la de guiar y apoyar el proceso, a partir de una actitud de apertura y "humildad" que favorezca un ambiente apropiado para el aprendizaje. Esto es, desde una posición que no enjuicia ni sanciona y, por tanto, no genera temor o inseguridad. La disposición, flexibilidad y accesibilidad del facilitador son atributos que los docentes consideran deseables en la tarea de acompañamiento.

\footnotetext{
Preocuparse mucho de que nos sintiéramos a gusto y cómodos y que no la sintiéramos al momento de hacer la observación de la clase, como un ojo inquisidor, como aquella persona que nos va a castigar, o va a hacer un juicio punitivo, sino que como 'un ojo más'. (GF 1, docente escuela 2)
}

$\mathrm{Al}$ contrastar la mirada de docentes y facilitadores emergen puntos de encuentro en relación con la relevancia que le atribuyen a la creación de un clima de confianza, basado en el reconocimiento y la retroalimentación positiva para acompañar el proceso de EC y favorecer el trabajo colaborativo. Los facilitadores resaltan la importancia de develar y valorar los saberes de los docentes como punto de partida para fortalecer su sentimiento 
de autoeficacia, destacando que la empatía, proporcionar estímulo y reducir la ansiedad, son fundamentales para construir un clima propicio para el cambio y la innovación desde un enfoque inclusivo.

\begin{abstract}
Nosotros no les íbamos a decir qué tenían que hacer, sino tratar de que emergieran esos saberes que uno confía que los profesores tienen, darle confianza al profesor, que si tiene ese espacio es para aprender. Es súper importante orientar y valorar los saberes y estrategias de los profesores. (GF3, facilitador 4)
\end{abstract}

Las y los facilitadores expresan que su rol en el acompañamiento del EC es el de conducir, guiar y mediar el proceso en una relación simétrica con los docentes. No obstante, señalan que, a pesar de establecerse relaciones más horizontales y de confianza, los docentes estaban expectantes de lo que dijera el facilitador y de sus valoraciones, probablemente porque le atribuyen un mayor conocimiento o jerarquía. En efecto, los docentes valoran los conocimientos del sistema educativo que poseen los facilitadores, especialmente en relación con las políticas públicas, la realidad de las escuelas, y el trabajo pedagógico desde una perspectiva inclusiva.

Nuestra facilitadora tenía conocimiento de las políticas públicas, del funcionamiento de la escuela y también conocimiento desde lo pedagógico, porque al mostrarle nuestra planificación ella también nos centraba. (GF 1, docente escuela 2)

Orientar el proceso de planificación, la reflexión y retroalimentación entre pares para favorecer la participación y aprendizaje de los estudiantes en la clase, aparece como otra de las funciones que relevan los facilitadores. Consideran que la principal contribución de la labor de acompañamiento es aportar una mirada externa que ayude a visibilizar aspectos críticos de la práctica, guiar la reflexión mediante preguntas, ofrecer opciones y buscar soluciones, ayudar a focalizarse en la tarea, o dirimir desacuerdos. Esta apreciación es coincidente entre docentes y facilitadores. Así se refiere a este respecto una facilitadora:

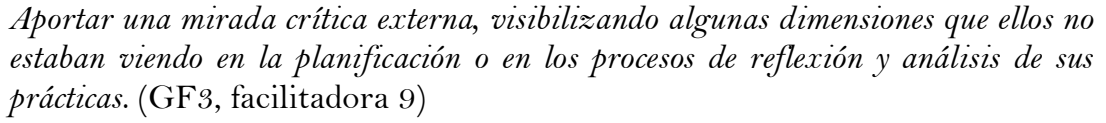

Adicionalmente, los docentes destacan los aportes de la observación de clase y la retroalimentación derivada de la misma, señalando la importancia de que se brinde preferentemente a continuación de la clase, porque posibilita incorporar los aportes o sugerencias en las fases siguientes del proceso.

Tiene que haber un feedback permanente como, por ejemplo, si uno va a ver una clase no puede ser después de dos semanas, sino que tiene que estar, así como fresquito, para poder decir ya, entonces estas cosas que no identificamos en esta clase, mejorémosla para el siguiente. (GF2, docente escuela 4)

Un desafío que surge de las reflexiones de los facilitadores es la necesidad de un mayor acercamiento y conocimiento de las escuelas y su cultura, que les permita ofrecer orientaciones más significativas y pertinentes al contexto y a las necesidades de cada equipo de EC. Asimismo, reconocen como aspectos críticos de la labor de acompañamiento, y que tendrían que seguir fortaleciendo, la capacidad para realizar observaciones más rigurosas y entregar retroalimentación de manera constructiva y sistemática.

Un desafío desde nuestro rol es 'apropiarse' de esa escuela, conocerla más, como es su dinámica, como es la relación con la UTP, con el director. Ese conocimiento lo necesitábamos porque finalmente llegabas como un externo. (GF3, facilitadora 5) 
Vinculado a lo anterior, varios docentes consideran que el acompañamiento debiera darse durante todo el proceso del EC. Piensan que de esta forma se podría llevar un seguimiento sistemático y continuo de las orientaciones o acuerdos tomados con el equipo de EC, asegurando que todos sus integrantes se beneficien de las observaciones del facilitador. Y, en el caso de surgir dificultades o imprevistos, disponer de alternativas de acompañamiento para que no se pierda la continuidad, factor indispensable para el buen desarrollo del proceso de reflexión acción colaborativa que esta metodología posibilita.

\section{Discusión y conclusiones}

Uno de los objetivos de la investigación fue indagar si el EC promovía cambios en las concepciones de los docentes y en el desarrollo de prácticas más inclusivas, que es la finalidad del proceso formativo. Al respecto, se puede concluir que, pese a que fue una experiencia acotada a tres sesiones que abarcaban las distintas fases del EC, se han producido cambios en las representaciones del profesorado en relación con la diversidad, la participación y el aprendizaje, que son tres dimensiones nucleares e interdependientes de la perspectiva de la inclusión (Ainscow, 2020a). Es importante destacar, además, que estos cambios en las creencias se han concretado en acciones, aunque es preciso que éstas se amplíen y se consoliden para avanzar hacia una cultura inclusiva en los centros, en la que toda la comunidad educativa, y no solo los participantes en el EC, comparta la filosofía y los valores de la inclusión y se comprometa con su puesta en práctica.

Otro aporte del EC ha sido el cambio de mirada sobre los estudiantes, aspecto de especial relevancia dada su influencia en la toma de decisiones pedagógicas y en la forma de relacionares con ellos (López et al., 2010). Centrar la mirada en los estudiantes es un espejo que les devuelve la mirada sobre sí mismos y les permite revisar su propia práctica y adoptar nuevas perspectivas para dar respuesta a la diversidad de sus estudiantes. Las y los docentes han ampliado su concepción de diversidad desde los estudiantes con algún tipo de dificultad hacia una noción más comprensiva que considera que todos son diferentes y tienen distintas necesidades, competencias, intereses y formas de aprender, lo cual es consistente con el hallazgo de la investigación realizada por Duk y Hernández (2020).

La ampliación del significado de diversidad ha supuesto cuestionarse el concepto de "normalidad" y del "estudiante promedio o ideal", que está fuertemente instalada en las planificaciones y prácticas educativas, así como de la tendencia a etiquetar a quienes no se ajustan a la norma (Muñoz et al., 2015) reconociendo que todos pueden aportar de diversas formas y centrándose más en sus fortalezas que en sus debilidades. La percepción que tienen los docentes sobre las características de sus estudiantes influye fuertemente en sus expectativas y en sus decisiones pedagógicas, tal como han mostrado diferentes estudios (Calderón et al., 2020; Hernández y Marchesi, 2021; Rojas et al., 2019) por lo que una apreciación positiva de los mismos contribuirá a que confíen en sus posibilidades y les planteen actividades más desafiantes y pertinentes que incrementen su aprendizaje y participación.

Uno de los mayores impactos del EC ha sido la toma de conciencia sobre la importancia de la participación de los estudiantes y de considerar sus puntos de vista en la toma de decisiones, lo cual además de fortalecer su protagonismo en el proceso de enseñanza y aprendizaje, implica un estatus diferente en la relación pedagógica de mayor reciprocidad y corresponsabilidad, donde el docente también aprende con y de sus estudiantes y 
enriquece su repertorio para dar una respuesta más pertinente a sus necesidades e intereses. Este aspecto ha sido el más novedoso para los docentes y el que ha suscitado más cambios en su práctica, lo cual se ha concretado mayormente en darles la posibilidad de elegir entre varias actividades o en la forma de desarrollarlas, en la autoevaluación y coevaluación de su aprendizaje, considerarlos en la planificación y retroalimentación de las clases, favoreciendo un mayor involucramiento de los estudiantes y una actitud más favorable al aprendizaje.

Este hallazgo también es consistente con los resultados de la investigación de Duk y Hernández (2020) y con investigaciones realizadas en países de la UE donde se destaca que considerar la voz de los estudiantes es el aspecto que marca la diferencia en la atención a la diversidad del alumnado porque tiene el potencial de desafiar a los docentes a explorar nuevas alternativas para implicar a los estudiantes de manera activa en las clases (Ainscow y Messiou, 2017; Messiou et al., 2016; Simón et al., 2018). El desafío es que la participación se convierta en una práctica sistemática involucrando a los estudiantes en todas las etapas del EC, especialmente en la planificación y revisión de las clases, y que se generalice a otras aulas de los centros educativos.

La metodología del EC ha favorecido la elaboración de planificaciones más diversificadas, lo que se ha traducido mayormente en el uso de una variedad de recursos y actividades para abordar los mismos objetivos, la conformación de grupos heterogéneos y la ruptura de la enseñanza frontal. Si bien es necesario profundizar en la comprensión y aplicación de todos los principios del DUA -en cuanto a diversas formas de motivación, presentación de contenidos, estrategias de enseñanza y de evaluación-, las y los docentes percibieron que las innovaciones implementadas incrementaron la participación en el aula. La dificultad de aplicar todos los principios del DUA en el desarrollo de las clases ha sido también constatada en otros estudios (Espada et al., 2019; Rao et al., 2016).

Un aspecto especialmente valorado por el profesorado ha sido el abordaje interdisciplinar de los contenidos, tanto por el apoyo y el enriquecimiento profesional que implicó el trabajo con otros docentes, como por las mayores posibilidades de participación y aprendizaje que les proporcionó a sus estudiantes, al brindarles múltiples perspectivas, estrategias y materiales para conocer un tema, haciendo que las clases fueran más pertinentes y creativas. Esto confirma lo que señalan algunos autores respecto a que la interdisciplinariedad favorece el aprendizaje significativo, porque no solo facilita la adquisición e integración de saberes sino diferentes formas de aprender (Bautista, 2015; Lenoir, 2013).

Un elemento que emerge con fuerza en todas las dimensiones estudiadas es la importancia que otorgan docentes y facilitadores a las competencias afectivas y relacionales, tanto en lo referido a la relación pedagógica con los estudiantes, como a la relación de colaboración entre docentes y entre docentes y facilitadores. Los aspectos más relevados son la apertura, la autocrítica, la flexibilidad, el respeto de las diferencias, la empatía, la confianza mutua, la capacidad de escucha, y las relaciones horizontales, entre otros. Este hallazgo es consistente con diferentes estudios que indican la influencia de los aspectos interpersonales en el éxito de la colaboración, indicando que cuando existen fuertes vínculos personales entre los docentes se genera una mayor cohesión y colaboración, a pesar de las barreras existentes a nivel organizacional e institucional (Rodríguez, 2014; Villa et al., 2008). 
Otro de los objetivos de este estudio fue indagar si el EC aplicado como estrategia formativa con foco en la diversidad contribuye al desarrollo profesional docente. Al respecto, los resultados de esta experiencia muestran las ventajas de esta metodología para el desarrollo de prácticas inclusivas. En primer término, porque exige trabajar en equipo, lo cual favorece el desarrollo de competencias de colaboración profesional entre pares, elemento fundamental para abordar los desafíos y transformaciones que demanda la inclusión, lo cual ha sido relevado por los participantes y ampliamente documentado por distintos autores (Ainscow, 2020a; Calvo, 2014; Messiou, 2018; Simón et al., 2018; Valliant, 2016).

En segundo término, el EC ha mostrado su potencial para promover la reflexión sobre la acción, desde una perspectiva inclusiva, generando un círculo virtuoso de mejora cuyo mayor valor radica en que posibilitó a los participantes problematizar y analizar sus prácticas en colaboración con otros. Este espacio de reflexión a través de fases secuenciales en las que tríos de docentes tuvieron la posibilidad de planificar, enseñar, observar y revisar la clase, les brindó oportunidades para volver a aplicar, observar, reflexionar y aprender de la experiencia, cumpliendo así con las condiciones propias de los procesos recursivos, que vuelven sobre sí mismos, desde una posición meta reflexiva (Soto y Pérez, 2015).

En tercer lugar, porque la implementación del EC en las escuelas públicas de Peñalolén ha permitido corroborar la importancia del aprendizaje situado en la escuela (Ainscow, 2020a; Calvo 2014; Vezub, 2010), así como lo demostrado por otros estudios respecto de las oportunidades que ofrece la reflexión compartida sobre los dilemas y problemas de la práctica, y cómo, a partir de ello, el profesorado aprende de los procesos de indagación colectiva, basados en el análisis de evidencias (Ainscow, 2020b; Calderón et al., 2020) que, en este caso, surgen de las prácticas de aula y la planificación colaborativa (Pérez y Soto, 2011).

Todo lo anterior es consistente con la amplia evidencia de la literatura que indica que el EC favorece el aprendizaje profesional colaborativo sobre la práctica (Messiou et al., 2014; Valliant 2016), en este caso trasladando el foco desde la enseñanza hacia el aprendizaje y participación de la diversidad del alumnado, mostrando similitudes con los hallazgos encontrados como resultado de proyectos de investigación acción colaborativa desarrollados en varios países europeos (Messiou et al., 2016; Messiou, 2018; Simón et al., 2018).

La investigación puso en evidencia la cultura de supervisión y evaluación del desempeño docente fuertemente instalada en Chile (Contreras, 2018), y cómo ésta dificulta focalizar la observación en las respuestas y participación de los estudiantes o, en cómo las estrategias y actividades implementadas durante el EC aportaban a la mejora de la respuesta a la diversidad. Esta dificultad también se observó en la retroalimentación, ya que tendía a vincularse más con las formas de enseñanza que con la participación de los estudiantes (Contreras, 2018). En este sentido, el rol de los facilitadores contribuyó a cambiar el significado de supervisión por el de acompañamiento, incentivando la mirada hacia los estudiantes y propiciando un espacio de confianza entre pares, reconociendo así la necesidad de ayudarse y colaborar para desarrollarse profesionalmente (Troncoso y Hawes, 2006, en Contreras, 2018).

Adicionalmente, si bien la retroalimentación logra realizarse en un espacio de confianza favorecido por los facilitadores, se aprecia una cierta dificultad para hacer un análisis 
crítico de la clase observada, que identifique con claridad los aciertos y aspectos a mejorar. Esto podría deberse al temor de verse expuesto, ya que la retroalimentación suele asociarse a una evaluación que no pone el foco en el proceso y en el acompañamiento sino más bien en la certificación de la formación (Contreras, 2018).

La investigación muestra de forma concluyente la importancia del proceso de acompañamiento por parte de las y los facilitadores, reconocido por los docentes. Este hallazgo es consistente con la evidencia disponible respecto a que los procesos formativos que apuestan a un cambio colectivo para la innovación y la transformación de la práctica requieren de apoyo y acompañamiento para orientar dicho proceso (Ainscow, 2020a; Montecinos, 2013). Para enfrentar este desafío, la figura del facilitador se convierte en una pieza clave del proceso porque ofrece una mirada externa que ayuda a visibilizar aspectos críticos de la práctica, guiar la reflexión y mediar la discusión pedagógica para abordar la diversidad en el aula. En este sentido, el proceso de acompañamiento añade valor al aprendizaje profesional y contribuyó de manera significativa a la valoración positiva de la formación recibida, constituyendo también una oportunidad para el desarrollo profesional de los facilitadores.

Dados los beneficios que ha mostrado el EC como herramienta para favorecer el desarrollo de prácticas más inclusivas, y la alta valoración de esta metodología por parte del profesorado, el desafío es que tenga continuidad y se pueda institucionalizar como una práctica habitual en los centros. Esto requiere una serie de condiciones que han sido relevadas en este estudio: i) disponer de tiempos y espacios suficientes para abordar todas las etapas del EC, lo cual es complejo debido la sobrecarga de tareas y de proyectos en las escuelas; ii) compromiso y visión compartida sobre la inclusión de todos los involucrados, relevando que el EC va a contramano de algunas políticas como por ejemplo el Sistema Nacional de Medición de la Calidad de la Educación; iii) voluntad política para generar las condiciones necesarias; iv) procesos sostenidos de formación para seguir fortaleciendo las competencias, especialmente en lo referido a la observación, el trabajo colaborativo, la diversificación de la enseñanza y de la evaluación; v) apoyo de los equipos directivos por su rol fundamental para movilizar al profesorado y facilitar los cambios organizativos necesarios para el trabajo colaborativo; vi) mayor autonomía para tomar decisiones pertinentes a las características de sus centros y estudiantes.

Con todo, varias de las conclusiones de nuestro estudio resultan coincidentes y complementarias con la revisión reciente sobre la contribución del EC realizada por Norwich y otros (2021). En primer lugar, tanto en esta revisión como en nuestro estudio se destaca el valor del EC como una estrategia de aprendizaje profesional docente que favorece el desarrollo de competencias centradas en la reflexión y análisis de la práctica, así como la mejora de la autoeficacia percibida por las y los docentes, lo que constituyen un requisito esencial para la mejora de los procesos de inclusión educativa. En este sentido, las valoraciones de los participantes de nuestro estudio apuntan a varios de los componentes cruciales de los modelos de pedagogía inclusiva o competencias docentes para la inclusión, tales como la valoración de la diversidad, el desarrollo de nuevas formas de apoyo al aprendizaje y la participación, y las competencias de trabajo colaborativo. Asimismo, tanto nuestro estudio como el de estos autores plantean como una preocupación necesaria de abordar en la práctica la de asegurar las condiciones institucionales para la sostenibilidad de las prácticas del EC. 
Por otra parte, es necesario señalar que debido a circunstancias del contexto como el estallido social ocurrido en Chile en 2018, que implicó paros docentes, y, posteriormente la pandemia por Covid-19, se alteró el cronograma inicial y hubo menor participación de la prevista inicialmente en el diseño de esta investigación. Ello obstaculizó la posibilidad de concretar entrevistas con directores de los centros, que hubieran aportado una visión más amplia del aporte del EC e impidió realizar un grupo focal con estudiantes como estaba previsto. No obstante, sus voces fueron recogidas durante el proceso de EC, aspecto que sería relevante considerar en futuras investigaciones, ya que los estudiantes podrían aportar información muy valiosa sobre el impacto de la experiencia en su proceso de aprendizaje y de participación.

Finalmente, cabe destacar que los hallazgos encontrados permiten contar con información valiosa para el diseño e implementación de procesos de desarrollo docente que puedan extenderse a otras comunas e instancias de formación. Asimismo, abre oportunidades para el inicio de una agenda de investigación que genere conocimientos teórico prácticos sobre esta estrategia formativa y sus efectos en los procesos de inclusión, mediante estudios específicos que permitan profundizar sobre aquellos aspectos más críticos o relevantes identificados en la presente investigación.

\section{Referencias}

Ainscow, M. (2005, 13 de enero). El próximo gran reto: la mejora de la escuela inclusiva. Presentación de apertura del Congreso sobre Efectividad y Mejora Escolar. Universitat de Barcelona,

Ainscow, M. (2016). Diversity and equity: A global education challenge. New Zealand Journal of Educational Studies, 51(2), 143-155. https://doi.org/10.1080/13632434.2012.669648

Ainscow, M. (2020a) Promoting inclusion and equity in education: lessons from international experiences. Nordic Journal of Studies in Educational Policy, 6(1), 7-16. https://doi.org/10.1080/20020317.2020.1729587

Ainscow, M. (2020b). Inclusion and equity in education: Making sense of global challenges. Prospects, 49,123-134. https://doi.org/10.1007/s11125-020-09506-w

Ainscow, M. y Messiou, K. (2017). Engaging with the views of students to promote inclusion in education. Journal of Educational Change, 19(1), 1-17.

https://doi.org/10.1007/s 10833-017-9312-1

Bautista, D. A. (2015). Relación entre procesos interdisciplinares en la calidad de la educación básica de Bogotá-Colombia en 2015. Itinerario Educativo, 66, 87-120. https://doi.org/10.21500/01212753.2215

Benavides, L. y Calvache, R. (2013). El estudio de clase como investigación en el aula. Revista Docencia e Investigación Universitaria, 2(1), 32-55.

Blanco, R. (2014). Inclusión educativa en América Latina: Caminos recorridos y por recorrer. En A. Marchesi, R. Blanco y L. Hernández (Coords.), Avances y desafíos de la educación inclusiva en Iberoamérica (pp. 11-36). OEI.

Blanco R. (2015). Formación continua en la comunidad iberoamericana. En R. Blanco (Ed.), Formación continua y desarrollo profesional docente (pp. 51-74). OEI.

Calderón-Almendros, I., Ainscow, M., Bersanelli, S. y Molina-Toledo, P. (2020). Educational inclusion and equity in Latin America: An analysis of the challenges. Prospects, 49, 169-186. https://doi.org/10.1007/s11125-020-09501-1 
Calvo, G. (2014). Desarrollo profesional docente: El aprendizaje profesional colaborativo. En UNESCO, Temas críticos para formular nuevas políticas docentes en América Latina y el Caribe: El debate actual (pp. 112-152). OREALC/UNESCO.

Castillo, P. y Miranda, C. (2018). Actitud hacia la inclusión de los estudiantes de pedagogía de una universidad estatal chilena. Revista Latinoamericana de Educación Inclusiva, 12(2), 133-148. https://doi.org/10.4067/S0718-73782018000200009

Cisternas, T. y Lobos, A. (2019). Profesores nóveles de enseñanza básica: Dilemas, estrategias y obstáculos para abordar los desafíos de una educación inclusiva. Revista Latinoamericana de Educación Inclusiva, 13(1), 37-53. https://doi.org/10.4067/S0718-73782019000100037

Contreras, G. A. (2018). Retroalimentación por pares en la docencia universitaria. Una alternativa de evaluación formativa. Formación Universitaria, 11(4), 83-94.

https://doi.org/10.4067/S0718-50062018000400083

Duk, C. (2014). La formación y el desarrollo profesional de los docentes para una educación inclusiva. En A. Marchesi, R. Blanco y L. Hernández (Coords.), Avances y desafíos de la educación inclusiva en Iberoamérica (pp. 61-70). OEI.

Duk, C., Cisternas, T. y Ramos, L. (2019). Formación docente desde un enfoque inclusivo. A 25 años de la Declaración de Salamanca, nuevos y viejos desafíos. Revista Latinoamericana de Educación Inclusiva, 13(2), 91-109. https://doi.org/10.4067/So7 18-73782019000200091

Duk, C. y Hernández-Ojeda, F. (2020). Mejorando la respuesta a la diversidad en el aula a través del estudio de clases en escuelas chilenas. Revista Internacional de Educación para la Justicia Social, 9(1), 99-123. https://doi.org/10.15366/riejs2020.9.1.005

Espada, R. M., Gallego, M. y González-Montesino, R. H. (2019). Diseño universal del aprendizaje e inclusión en la educación básica. Alteridad, 14(2), 207-218. https://doi.org/10.17163/alt.v14n2.2019.05

European Commission. (2017). Preparing teachers for diversity. The role of initial teacher education: Final report. European Union.

Gibbs, G. (2012). El análisis de datos cualitativos en investigación cualitativa. Morata.

González-Gil, F., Martín-Pastor, E., Flores, N., Jenaro, C., Poy, R. y Gómez-Vela, M. (2013). Teaching, learning and inclusive education: The challenge of teachers' training for inclusion. Procedia Social and Behavioral Sciences, 93, 783-788. https://doi.org/10.1016/j.sbspro.2013.09.279

González-Gil, F., Martin-Pastor, E., Poy, R. y Jenaro, C. (2016). Percepciones del profesorado sobre la inclusión: estudio preliminar. Revista Electrónica Interuniversitaria de Formación del Profesorado, 19(3), 11-24. https://doi.org/10.6018/reifop.19.3.219321

Hernández, L. y Marchesi, Á. (2021). Actitudes de los maestros ante la inclusión educativa en Colombia, Guatemala y España. Ciencia y Educación, 5(1), 7-24. https://doi.org/10.22206/cyed.2021.v5i1.pp7-24

Jortveit, M. y Kovač, B. V. (2021). Co-teaching that works: special and general educators' perspectives on collaboration. Teaching Education, 13(2), 1-15.

Krichesky, G. J. y Murillo F. J. (2018). La colaboración docente como factor de aprendizaje y promotor de mejora. Un estudio de casos. Educación XXI, 21(1), 135-156.

Lenoir, Y. (2013). Interdisciplinariedad en educación: una síntesis de sus especificidades y actualización. Interdisciplina, 1(1), 52-86. https://doi.org/10.22201/ceiich.24485705e.2013.1.46514 
López, M., Echeita, G. y Martín, E. (2010). Dilemas en los procesos de inclusión: Explorando instrumentos para una comprensión de las concepciones educativas del profesorado. Revista Latinoamericana de Educación Inclusiva, 4(2), 155-176.

Manos, A., April, D., Barakat, B., Bella, N., D’Addio, A C., Eck, M., Endrizzi, F., Joshi, P., Kubacka, K., McWilliam, A., Murakami, Y., Smith, W., Stipanovic, L., Vidarte, R. y Zekrya, L. (2020). All means all: An introduction to the 2020 Global Education Monitoring Report on Inclusion. Prospects, 49, 103-109, UNESCO.

Mella, O. (2000). Grupos focales. Técnica de investigación cualitativa. CIDE.

Messiou, K. (2018). Collaborative action research: Facilitating inclusion in schools. Educational Action Research, 27(2), 197-209. https://doi.org/10.1080/09650792.2018.1436081

Messiou, K., Ainscow, M. y Echeita, G. (Coord.) (2014). El desafío de la diversidad. Un estímulo para el desarrollo profesional. Cuadernos de Pedagogía, 446, 41-67.

Messiou, K., Ainscow, M., Echeita, G., Goldrick, S., Hope, M., Paes, I., Sandoval, M., Simón, C. y Vitorino, T. (2016). Learning from differences: A strategy for teacher development in respect to student diversity. Journal School Effectiveness and School Improvement, 27(1), 45-61. https://doi.org/10.1080/09243453.2014.966726

Ministerio de Educación. (2017). Informe consultas participativas de voces docentes. CPEIP.

Montecinos, C. (2003). Desarrollo profesional docente y aprendizaje colectivo. Psicoperspectivas, 2, 105-128.

Muñoz, M., López, M. y Assaél, J. (2015). Concepciones docentes para responder a la diversidad: ¿Barreras o recursos para la inclusión educativa? Psicoperspectivas, 14(3), 68-79.

Norwich, B., Benham-Clarke, S. y Goei, S. (2021). Review of research literature about the use of lesson study and lesson study-related practices relevant to the field of special needs and inclusive education. European Journal of Special Needs Education, 36(3), 309-328. https://doi.org/10.1080/08856257.2020.1755929

OECD. (2014). TALIS 2013 Results: An international perspective on teaching and learning. OECD Publishing. https://doi.org/10.1787/9789264196261-en

OECD. (2019). TALIS 2018 Results (volume I): teachers and school leaders as lifelong learners. OECD Publishing. https://doi.org/10.1787/1dobc92a-en

Pérez, A. y Soto, E. (2011). Lesson study. La mejora de la práctica y la investigación docente. Cuadernos de Pedagogía, 41 7, 64-67.

Rao, K., Currie-Rubin, R. y Logli C. (2016). Diseño iniversal para el Aprendizaje y prácticas inclusivas en los colegios del mundo del IB. CAST.

Rapley, T. (2007). Los análisis de la conversación, del discurso y de documentos en investigación cualitativa. Morata

Rodríguez, F. (2014). La co-enseñanza, una estrategia para el mejoramiento educativo y la inclusión. Revista Latinoamericana de Educación Inclusiva, 8(2), 219-233.

Rojas, C., López, M. y Echeita, G. (2019). Significados de las prácticas escolares que buscan responder a la diversidad desde la perspectiva de niñas y niños: Una aproximación a la justicia educacional. Perspectiva Educacional, 58(2), 23-46. https://doi.org/10.4151/07189729-Vol.58-Iss.2-Art.912

Sharma, U. y Mullik, J. (2021). Bridging the gaps between theory and practice of inclusive teacher education. https://doi.org/10.1093/acrefore/9780190264093.013.1226 
Simón, C., Echeita, G. y Sandoval, M. (2018). La incorporación de la voz del alumnado a la 'lesson study' como estrategia de formación docente y mejora para la inclusión. Cultura y Educación, 3O(1), 205-225. https://doi.org/10.1080/11356405.2017.1416741

Soto, E., y Pérez, A.I. (2015). Lesson studies: Un viaje de ida y vuelta recreando el aprendizaje comprensivo. Revista Interuniversitaria de Formación del Profesorado, 84(293), 15-28.

Troncoso, K. y Hawes, G. (2006) A propósito de la evaluación por pares: La necesidad de semantizar la evaluación y las prácticas docentes. Perspectiva Educacional, 48, 59-73.

UNESCO. (2015). Incheon declaration and framework for action for the implementation of sustainable development goal 4. UNESCO.

UNESCO. (2017). Guía para asegurar la inclusión y equidad en la educación. UNESCO.

Urbina, C., Basualto, P., Durán C. y Miranda, P. (2017). Prácticas de co-docencia: El caso de una dupla en el marco del programa de integración escolar en Chile. Estudios Pedagógicos, 43(2), 355-374. https://doi.org/10.4067/S0718-07052017000200019

Vaillant, D. (2016). Trabajo colaborativo y nuevos escenarios para el desarrollo profesional docente. Revista Docencia, 60, 5-13

Vermunt, J. D., Vrikki, M., Van Halem, N., Warwick, P. y Mercer, N. (2019). The impact of lesson study professional development on the quality of teacher learning. Teaching and Teacher Education, 81(1), 61-73. https://doi.org/10.1016/j.tate.2019.02.009

Vezub, L. (2010). El desarrollo profesional docente centrado en la escuela: Concepciones, políticas y experiencias. UNESCO.

Villa, R., Thousand, J. y Nevin, A. (2008). A guide to co-teaching. Practical tips for facilitating student learning. Corwin Press.

Ydo Y., (2020). Inclusive education: global priority, collective responsibility. Prospects 49, 97-101. https://doi.org/10.1007/s11125-020-09520-y

\section{Breve CV de los/as autores/as}

\section{Cynthia Duk}

Directora del Centro de Desarrollo e Innovación en Educación Inclusiva y del programa de Magíster en Educación Inclusiva de la Universidad Central de Chile. Además, es directora de la Revista Latinoamericana de Educación Inclusiva que publica la Facultad de Educación en colaboración con la Red Iberoamericana de Investigación RINACE. Su línea principal de desarrollo e investigación es la inclusión y la diversidad, con énfasis en el desarrollo de escuelas y sistemas educativos inclusivos. Como consultora ha colaborado en el desarrollo de políticas y prácticas inclusivas con distintos organismos internacionales y Ministerios de Educación de Latinoamérica. Ha diseñado diversos programas de formación continua, entre otros, el material Educar en la Diversidad para los países del MERCOSUR y el Diplomado on line de la OEI, Escuelas Inclusivas: enseñar y aprender en la diversidad”.Email: cduk@ucentral.cl

ORCID ID: http://orcid.org/OOOO-0002-8443-0707

\section{Rosa Blanco}

Coordinadora de proyectos y estudios de la Fundación Hineni. Fue especialista en educación inclusiva y educación de la primera infancia en la Oficina Regional de Educación 
de la UNESCO para América Latina y el Caribe (UNESCO/Santiago) y coordinadora de la red regional de innovaciones educativas para América Latina y el Caribe "Innovemos", ejerciendo como directora interina entre 2007-2008. Posteriormente fue directora de la oficina en Chile de la Organización de Estados Iberoamericanos para la Educación, la Ciencia y la Cultura (OEI/Chile), y directora del Instituto Iberoamericano de la Primera Infancia. Profesora invitada en programas de magister en la Universidad de Chile, la Universidad Central de Chile y la Universidad Católica de Córdoba, Argentina. Ha participado en grupos de expertos sobre reformas educativas, derechos de las personas con discapacidad y políticas de inclusión educativa. Email: rblanco.guijarro@gmail.com

ORCID ID: https://orcid.org/0000-0001-6263-3004

\section{Fiorella Zecchetto}

Licenciada en Literatura y Lingüística Hispánicas, Pontificia Universidad Católica de Chile. Magíster en Educación Inclusiva por la Universidad de Glasgow, Escocia. Es docente de postgrado del Magíster en Educación Inclusiva y coordinadora de programas de formación continua en Fundación Hineni y en el Centro de Desarrollo e Innovación en Educación Inclusiva, de la Facultad de Educación y Ciencias Sociales de la Universidad Central de Chile. Ha participado en el diseño y ejercido docencia en programas de perfeccionamiento docente en el área de la inclusión educativa en diversas casas de estudio. En investigación, sus áreas de interés son las concepciones y actitudes del profesorado respecto de la diversidad y la inclusión, la diversificación curricular, la participación estudiantil en el contexto escolar y el desarrollo profesional para la atención a la diversidad. Email: flowering@gmail.com

ORCID ID: https://orcid.org/0000-0002-3023-3011

\section{Carla Capell}

Profesora de Educación General Básica (Universidad Metropolitana de Ciencias de la Educación, Chile) Magíster en Docencia Universitaria e Investigación (Universidad Central Chile) y Máster en Integración Social de personas con discapacidad (Universidad de Salamanca). Concentra su trabajo en la Agencia de Calidad de la Educación como parte del equipo de Formación Continua en la División de Evaluación y Orientación de Desempeño (ACE. Chile). Consultora en el Comité de Área de Educación Básica, Párvulo y Educación Diferencial de la Comisión Nacional de Acreditación (CNA. Chile). Docente postgrado en el Magister en Educación Inclusiva; Magister de Gestión y Liderazgo Educacional y en Programas de Formación Continua a profesores(as) en ejercicio a través del Centro de Desarrollo e Innovación en Educación Inclusiva (Universidad Central Chile).Email: carlacapellgon@gmail.com

ORCID ID: https://orcid.org/0000-0002-7527-807x

\section{Mauricio López}

Profesor asociado del Departamento de Psicología de la Universidad de Chile. Psicólogo por la Universidad de Chile y Doctor en Psicología por la Universidad Autónoma de Madrid. Miembro del claustro académico del Magister en Psicología Educacional y Doctorado en Psicología de la Universidad de Chile. Ha desarrollado labores profesionales de asesoramiento a establecimientos educacionales y actividades de formación continua de docentes y profesionales de la educación. Su trabajo de investigación se ha orientado a 
examinar procesos psicológicos en contextos educativos relevantes para la inclusión, tales como el juego, la participación y la resolución colaborativa de problemas, desde una perspectiva sociocultural y de la diversidad. Coordinador de Psicología Educacional del Comité científico del XV Congreso Chileno de Psicología de la Red de Escuelas de Psicología de las Universidades del Estado de Chile. Email: m.lopez@uchile.cl

ORCID ID: https://orcid.org/0000-0002-8288-2988 